Disclosure of Interests: None declared

DOI: 10.1136/annrheumdis-2020-eular.5520

\begin{tabular}{|l|l}
\hline THU0558 & ANTI-CCP NEGATIVE PATIENTS WITH NEW \\
MUSCULOSKELETAL SYMPTOMS: IMPROVING \\
REFERRALS FROM PRIMARY CARE
\end{tabular}

L. Garcia-Montoya ${ }^{1,2}$, J. Nam ${ }^{1,2}$, K. Mankia ${ }^{1,2}$, L. Duquenne ${ }^{1,2}$, A. DI Matteo ${ }^{1,2}$ P. Emery ${ }^{1}{ }^{1}$ LIRMM, Leeds, United Kingdom; ${ }^{2}$ Leeds Biomedical Research Centre, NIHR, Leeds, United Kingdom

Background: The presence of anti-cyclic citrullinated peptide antibodies (antiCCP antibodies) is associated with progression to inflammatory arthritis (IA) [1]; however, most patients attending primary care with a new non-specific musculoskeletal (MSK) complaint and no clinical synovitis have a negative result for this test (CCP-). Considering that only a small proportion of these individuals will be diagnosed with an IA within the next 12 months, predicting disease progression in these patients appears to be more challenging.

Objectives: To investigate factors that could be associated with disease progression in patients testing CCP- in order to optimise primary care referrals to Rheumatology.

Methods: A prospective observational study recruiting patients over 16 years old with a new MSK complaint and no clinical synovitis was conducted. Patients recruited from primary care centres across the UK from July 2007 until November 2018 were included in this analysis. Those testing negative for the anti-CCP2 assay (initially phadia, later bioplex) were sent questionnaires 1 year later, and GPs were contacted in November 2019 to confirm their disease status.

Results: 7521 eligible patients were recruited from primary care. $7290(97 \%)$ of them were CCP- and 5678 returned the questionnaire after 1 year. 239 patients $(4.2 \%)$ of these CCP- reported progression to IA; however, this diagnosis was only confirmed in 53 of them $(0.93 \%)$. In another 38 patients, the IA diagnosis could not be confirmed and therefore they were not included in the analysis. 21 patients progressed to rheumatoid arthritis (RA), 13 to spondyloarthritis, 11 to polymyalgia rheumatica (requiring disease-modifying anti-rheumatic drugs), 3 to polymyositis, 3 to systemic lupus erythematosus and 2 to systemic sclerosis. Table 1 describes the most troublesome joints and table 2 other concomitant MSK diagnoses of the non-progressors/ progressors; and among the last ones, the RA group. Multivariable analysis showed that pain in specific joints was associated with development of IA within the following 12 months: hand odds ratio (OR) $2.1[95 \% \mathrm{Cl}(1.09-4.16), \mathrm{p}=0.027]$, knee OR $2.0[95 \% \mathrm{Cl}(1.13-3.91)$, $\mathrm{p}=0.02]$, and shoulder OR 1.8 [95\% Cl (1.02-3.45), $\mathrm{p}=0.043)$. Smoking exposure, having a first degree relative with RA and gender were not predictive for progression. Older age showed only a slightly higher risk for IA [OR $1.04,95 \% \mathrm{CI}$ (1.01-1.06) $p=0.001]$.

Table 1. Characteristics, troublesome joints of the participants

\begin{tabular}{lccc}
\hline & $\begin{array}{c}\text { NON-PROGRESSORS } \\
(\mathbf{n = 5 5 8 8})\end{array}$ & $\begin{array}{c}\text { PROGRESSORS } \\
(\mathbf{n = 5 2 )}\end{array}$ & $\begin{array}{c}\text { RA progressors } \\
(\mathbf{n = 2 1 )}\end{array}$ \\
\hline Female \% & 72 & 58 & 57 \\
Mean age y.o. & $53(16-91)$ & $60(30-82)$ & $60(30-82)$ \\
FDR with RA \% & 38 & 33 & 33 \\
Ever Smoked \% & 38 & 43 & 40 \\
Neck pain \% & 30 & 29 & 14 \\
Shoulder pain \% & 41 & 58 & 52 \\
Elbow pain \% & 29 & 38 & 29 \\
Wrist pain \% & 38 & 46 & 48 \\
Hand pain \% & 53 & 71 & 76 \\
Thumb pain \% & 36 & 48 & 57 \\
Back pain \% & 33 & 25 & 24 \\
Hip pain \% & 36 & 29 & 62 \\
Knee pain \% & 55 & 71 & 24 \\
Ankle pain \% & 30 & 23 & 33 \\
Foot pain \% & 34 & 40 & \\
\hline
\end{tabular}

Table 2. Concomitant MSK diagnosis

\begin{tabular}{lccc}
\hline & $\begin{array}{c}\text { NON-PROGRESSORS } \\
(\mathbf{n}=\mathbf{5 5 8 8})\end{array}$ & $\begin{array}{c}\text { PROGRESSORS } \\
(\mathbf{n}=\mathbf{5 2})\end{array}$ & $\begin{array}{c}\text { RA progressors } \\
(\mathbf{n}=\mathbf{2 1})\end{array}$ \\
\hline Carpal tunnel & 13 & 17 & 30 \\
syndrome\% & & & \\
Rotator cuff \% & 12 & 19 & 20 \\
Trigger finger \% & 5 & 4 & 0 \\
Tennis elbow \% & 15 & 10 & 5 \\
Osteoarthritis \% & 18 & 25 & 20 \\
\hline
\end{tabular}

Conclusion: In CCP- patients without clinical synovitis, hand, knee and shoulder pain should be investigated more carefully as these involve a higher risk of progression to IA. Patient reported outcomes regarding rheumatic diseases are not reliable; the distribution of joint pain seems to be a more useful tool than the family history when assessing the need for referral to Rheumatology.

References:

[1] Rakieh C. Ann Rheum Dis. 2015;74:1659-66

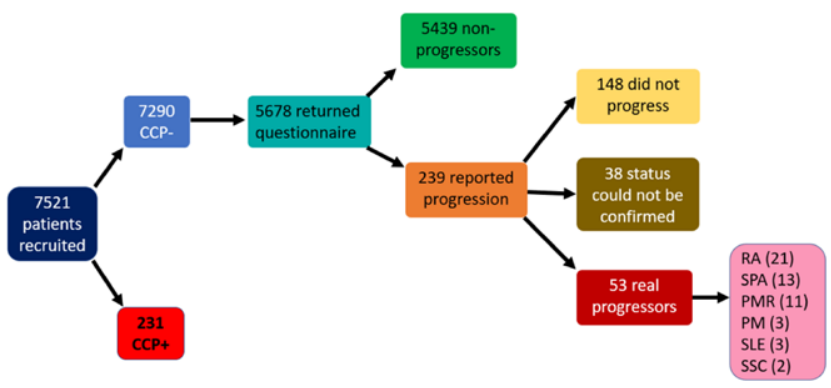

Figure 1. Study participants and outcome

Acknowledgments: National Institute of Health Research (NIHR) Leeds Biomedical Research Centre (BRC)

Disclosure of Interests: Leticia Garcia-Montoya: None declared, Jacqueline Nam: None declared, Kulveer Mankia: None declared, Laurence Duquenne: None declared, Andrea Di Matteo Grant/research support from: the publication was conducted while Dr. Di Matteo was an ARTICULUM fellow, Paul Emery Grant/research support from: AbbVie, Bristol-Myers Squibb, Merck Sharp \& Dohme, Pfizer, Roche (all paid to employer), Consultant of: AbbVie (consultant, clinical trials, advisor), Bristol-Myers Squibb (consultant, clinical trials, advisor), Lilly (clinical trials, advisor), Merck Sharp \& Dohme (consultant, clinical trials, advisor), Novartis (consultant, clinical trials, advisor), Pfizer (consultant, clinical trials, advisor), Roche (consultant, clinical trials, advisor), Samsung (clinical trials, advisor), Sandoz (clinical trials, advisor), UCB (consultant, clinical trials, advisor)

DOI: 10.1136/annrheumdis-2020-eular.3755

\section{THU0559 IMPLEMENTATION OF A TRIAGE SYSTEM IN A HOSPITAL WITH HIGH DEMAND FOR CARE}

S. Ibáñez ${ }^{1,2}$, F. Valenzuela ${ }^{1}$, O. Martinez ${ }^{1}$, O. Valenzuela ${ }^{1,2}$, F. Silva $^{1,2}$, M. J. Villar ${ }^{1,2}$, M. P. Poblete ${ }^{1}$, C. Mardones ${ }^{1} .{ }^{1}$ Hospital Padre Hurtado, San Ramón, Chile; ${ }^{2}$ Clinica Alemana, Vitacura, Chile

Background: Our hospital has 4 Rheumatologists and is in charge of 425.000 inhabitants (1 rheumatologist per 106.250 inhabitants). In November 2017, there were 503 referrals from primary care waiting for a first visit with the rheumatologist. Given the impossibility of covering this number of waiting patients through normal operation, it was decided to implement a rapid access polyclinic that started in December of 2017.

Objectives: To evaluate the effectiveness of a triage system in a center with high demand for care.

Methods: Patients referred by the general practitioner were evaluated by a senior rheumatologist in a 10-minute consultation using a predefined interrogation, expanded case-by-case based on the criteria of each rheumatologist. According to the results of the interview, the situation of the patient was categorized into: urgent, normal rheumatology control or control in primary care. For urgent consultations, an early control polyclinic was created to evaluate these patients within the following 15 days. The usual consultations entered into the usual scheduling system. The pathologies that were considered to require control in primary care were assigned to a coordination polyclinic where the patients were evaluated by an internist, in charge of confirming the diagnosis, educating the patient, and, if applicable, refer to primary care. No patient was discharged immediately after the triage. We report the data of the first 136 patients.

Results: The waiting time was reduced from a median of 275 days (IQR 66-591) to 46.5 (23-140). Refer to table 1 for full results. In $52.2 \%$ of referred patients the suspicion of a chronic autoimmune or inflammatory disease was described in the referral note. In these patients, when comparing with patients whose referral notes did not refer to an inflammatory or autoimmune disease, the waiting time for triage was significantly shorter, the percentage of patients who were discharged from rheumatology was significantly lower, and the percentage of patients in whom a chronic autoimmune or inflammatory disease was confirmed in the first control was significantly higher. 
Table 1

\begin{tabular}{|c|c|c|c|c|}
\hline & $\begin{array}{c}\text { All } \\
\text { patients }\end{array}$ & $\begin{array}{l}\text { Only those with sus- } \\
\text { pected autoimmune or } \\
\text { chronic inflammatory } \\
\text { disease in referral note }\end{array}$ & $\begin{array}{l}\text { Patients referred for other } \\
\text { reasons (fibromyalgia, } \\
\text { arthralgia, myalgia, } \\
\text { osteoporosis, etc.) }\end{array}$ & p \\
\hline Number (\%) & $136(100)$ & 71 (52.2) & $65(47.8)$ & NA \\
\hline $\begin{array}{l}\text { Age, mean years } \\
\text { (SD) }\end{array}$ & $51.8(16.3)$ & $50.7(16.4)$ & $53.1(16.2)$ & NS \\
\hline Men, n (\%) & 24 (17.6) & $15(21.1)$ & $9(13.8)$ & NS \\
\hline $\begin{array}{l}\text { Time between } \\
\text { referral and } \\
\text { triage, median } \\
\text { days (IQR) } \\
\text { Triage resolution }\end{array}$ & $\begin{array}{c}46.5 \\
(23-140)\end{array}$ & $34(15.5-124.5)$ & $54(28-441)$ & 0,017 \\
\hline $\begin{array}{l}\text { Urgent control, } \\
\mathrm{n}(\%)\end{array}$ & $92(67.6)$ & $55(77.5)$ & 37 (56.9) & 0,011 \\
\hline $\begin{array}{l}\text { Normal Control, } \\
\mathrm{n}(\%)\end{array}$ & $25(18.4)$ & $12(16.9)$ & $13(20)$ & NS \\
\hline $\begin{array}{l}\text { Primary care } \\
\text { coordination, } \\
\mathrm{n}(\%)\end{array}$ & $19(14)$ & $4(5.6)$ & $15(23.1)$ & 0,003 \\
\hline $\begin{array}{l}\text { Time between } \\
\text { triage and first } \\
\text { control, median } \\
\text { days (IQR) }\end{array}$ & $21(14-42)$ & $21(12.5-41)$ & $26(21-42)$ & NS \\
\hline $\begin{array}{l}\text { First control res- } \\
\text { olution, } \mathrm{n}(\%)\end{array}$ & $96(70.6)$ & $54(76.1)$ & $42(64.6)$ & NS \\
\hline $\begin{array}{l}\text { Diagnosis confir- } \\
\text { mation, } \mathrm{n}(\%)\end{array}$ & 37 (38.5) & $26(48.1)$ & $11(16.9)$ & 0,028 \\
\hline $\begin{array}{l}\text { Continue control, } \\
\mathrm{n}(\%)\end{array}$ & , 41 (42.7) & $26(48.1)$ & $15(23.1)$ & NS \\
\hline $\begin{array}{l}\text { Discharge to } \\
\text { primary care, } \\
\mathrm{n}(\%)\end{array}$ & $18(18.8)$ & $2(3.7)$ & $16(24.6)$ & $<0,001$ \\
\hline
\end{tabular}

SD: standard deviation; $n$ : number; IQR: Interquartile range

Conclusion: We consider this strategy as successful in reducing care times and identifying patients who require an early start of treatment and close control. Referral notes from primary care were generally adequate to identify patients who required to continue rheumatologist control.

References: None.

Disclosure of Interests: Sebastian Ibáñez Consultant of: Novartis, Paid instructor for: Bristol Myers, Speakers bureau: Abbvie, Francisca Valenzuela: None declared, Oriela Martinez: None declared, Omar Valenzuela Consultant of: Bristol Myers, Paid instructor for: Bristol Myers, Speakers bureau: Bristol Myers, Abbvie, Francisco Silva Consultant of: Roche, Speakers bureau: Roche, María José Villar: None declared, María Paz Poblete: None declared, Claudia Mardones: None declared

DOI: 10.1136/annrheumdis-2020-eular.4905

\section{THU0560 PRIMARY CARE PHYSICIAN PERSPECTIVES ON DELAYS IN DIAGNOSIS OF AXIAL SPONDYLOARTHRITIS: A QUALITATIVE STUDY}

S. H. Liu' ${ }^{1}$ K. Lapane ${ }^{1}$, D. Shridharmurthy ${ }^{1}$, S. Khan ${ }^{1}$, K. Ferrucci ${ }^{1}$, C. Dubé ${ }^{1}$, E. Yi ${ }^{2}$, J. Kay ${ }^{1,3} \cdot{ }^{1}$ University of Massachusetts Medical School, Population and Quantitative Health Sciences, Worcester, United States of America; ${ }^{2}$ Novartis Pharmaceuticals Corporation, HE\&OR and Medical Access, US Clinical Development and Medical Affairs, East Hanover, United States of America; ${ }^{3}$ University of Massachusetts Medical School, Medicine, WORCESTER, United States of America

Background: The average delay in diagnosis for patients with any form of spondyloarthritis $(\mathrm{SpA})$ ranges from 7 to 10 years [1-5]. In axial spondyloarthritis $(\operatorname{axSpA})$, a subgroup of $\mathrm{SpA}$, it is 5 to 14 years $[4,6,7]$. Factors that contribute to this delay include the lack of diagnostic criteria for axSpA and the difficulty in distinguishing inflammatory back pain (IBP), a key symptom of axSpA, from other highly prevalent forms of low back pain [8-10]. This impedes timely referral of these patients to rheumatologic care and initiation of appropriate treatment.

Objectives: Describe understanding of, attitudes towards, and practices regarding axSpA among primary care physicians.

Methods: We recruited 18 primary care physicians practicing in the United States as part of a larger qualitative study: the SpondyloArthritis Screening and Early Detection (SpA-SED) Study. We used purposive sampling with a goal of including an equal number of family medicine and internal medicine physicians who were balanced by gender. Physicians provided informed consent to participate in an in-depth interview (up to 60 minutes), conducted in person $(n=3)$ or over the phone $(n=15)$, between February and May 2019. The interview guide was developed by a multidisciplinary team, with input from rheumatologists. Topics included the physicians' approaches to evaluating back pain, their awareness about axSpA, their differential diagnosis of axSpA, the laboratory tests and imaging studies ordered when axSpA is suspected, their referral patterns for patients with presumed axSpA, their thoughts about factors contributing to diagnostic delay in axSpA, and their opinions about an Inflammatory Back Pain Assessment - ASAS criteria screening tool [5].

Results: Barriers to early diagnosis included patient factors (eg, multiple complaints, back pain not being the chief complaint), disease characteristics (eg, slow rate of disease progression), physician characteristics (eg, lack of rapport between patients and their primary care physicians), and structural/system issues (eg, lack of time). Most physicians reported that they would perform laboratory tests before referring a patient to a rheumatologist.

Conclusion: Primary care physicians were surprised to learn of the average delay to axSpA diagnosis, considered that this lengthy delay was problematic, and agreed that improvements are needed in screening for and early detection of axSpA. Physicians believed that there would be a role for using a screening tool in the primary care setting to improve diagnostic delay, but that evidence to support its implementation is needed.

References:

[1] Dougados M et al. Arthritis Rheum. 1991;34:1218-27.

[2] Amor B et al. Rev Rhum Mal Osteoartic. 1990;57:85-9.

[3] van der Linden S et al. Arthritis Rheum. 1984;27:361-8.

[4] Deodhar A et al. Arthritis Rheumatol. 2016;68:1669-76.

[5] Sieper J et al. Ann Rheum Dis. 2009;68:784-8.

[6] Sykes MP et al. Rheumatology (Oxford). 2015;54:2283-4.

[7] Redeker I et al. Rheumatology (Oxford). 2019;58:1634-8.

[8] Strand V et al. Mayo Clin Proc. 2017;92:555-64.

[9] Proft F et al. Ther Adv Musculoskelet Dis. 2018;10:129-39.

[10] Bohn R et al. Clin Exp Rheumatol. 2018;36: 263-74.

Acknowledgments: We thank the participants for sharing their insights as part of this study. This abstract was written using data from a research study originally funded by Novartis (Principal Investigator: Shao-Hsien Liu, Co-Investigators: Jonathan Kay, Kate Lapane, Catherine Dubé)

Disclosure of Interests: Shao-Hsien Liu Grant/research support from: Novartis Pharmaceuticals Corporation, Kate Lapane Grant/research support from: Novartis Pharmaceuticals Corporation, Divya Shridharmurthy Grant/research support from: Novartis Pharmaceuticals Corporation, Sara Khan Grant/ research support from: Novartis Pharmaceuticals Corporation, Katarina Ferrucci Grant/research support from: Novartis Pharmaceuticals Corporation Catherine Dubé Grant/research support from: Novartis Pharmaceuticals Corporation, Esther Yi Employee of: Novartis Pharmaceuticals Corporation, Jonathan Kay Grant/research support from: Gilead Sciences, Inc., Pfizer, Novartis Pharmaceuticals Corporation, Consultant of: Alvotech Suisse AG; Arena Pharmaceuticals, Inc.; Boehringer Ingelheim GmbH; Celltrion Healthcare Co. Ltd.; Merck Sharp \& Dohme Corp.; Mylan Inc.; Novartis AG; Samsung Bioepis; Sandoz, Inc; UCB, Inc.

DOI: 10.1136/annrheumdis-2020-eular.2004

\section{THU0561 PREDICTING LIVER TOXICITY CAUSED BY CONVENTIONAL SYNTHETIC DISEASE-MODIFYING ANTIRHEUMATIC DRUGS}

L. Kuusalo $^{1}$, M. Venäläinen ${ }^{2}$, S. Saranpää ${ }^{3}$, H. Kirjala ${ }^{3}$, L. Elo ${ }^{2}$, L. Pirilä ${ }^{1}$. ${ }^{1}$ University of Turku and Turku University Hospital, Center for Rheumatology and Clinical Immunology, Turku, Finland; ${ }^{2}$ University of Turku, Turku Bioscience Center, Turku, Finland; ${ }^{3}$ University of Turku, Turku, Finland

Background: Routine laboratory testing is recommended for early identification of toxicity during conventional synthetic disease modifying antirheumatic drug (csDMARD) treatment. Based on expert consensus, testing is recommended every 2-4 weeks for the first 3 moths and quarterly thereafter (1).

Objectives: In addition to evaluating the incidence of alanine transaminase (ALT) elevations in rheumatoid arthritis (RA) patients initiated on 1-2 csDMARDs, we aimed to distinguish patterns in ALT levels to develop a model for identifying patients at high risk for liver toxicity.

Methods: We identified RA patients who were initiated a new csDMARD course at the rheumatology clinic of Turku University Hospital in 2013-2019. Baseline and follow-up safety monitoring results were drawn from the electronic health record (EHR) data. Data on diagnoses and csDMARD initiation/cessation dates were manually confirmed from the EHR.

As the primary endpoint, we used ALT-elevations of more than twice the upper limit of reference range (women $\geq 70 \mathrm{U} / \mathrm{l}$, men $\geq 100 \mathrm{U} / \mathrm{I}$ ) within 6 months after treatment initiation. Intergroup differences were tested using Mann-Whitney test for continuous variables and the chi-square test or Fisher's exact test $(n<5)$ for categorical variables. Associations between different 